\title{
THE IMPLEMENTATION OF AGILE PROJECT MANAGEMENT IN THE FAST FASHION INDUSTRY
}

\author{
Aleksandra Atanacković \\ FishingBooker, Belgrade, Serbia
}

\begin{abstract}
In the world of fast fashion, the focus isn't on price competition any more, and the efforts of all of the subjects in the supply chain are directed toward creating as many product collections in as little time possible (Birtwistle, Fiorito, Siddiqui, 2003). Because of this, fashion companies use project management and strategies such as agile supply chains and quick response systems, insuring that they can meet customers' wants, flexibility, and easier communication in the process which begins with the idea about creating a certain product and ends with this product on shelves, available to the customers in the retail market. This paper intends to show how the fashion industry has changed in the past 30 years, and in which ways it has directed its efforts to more agile practices in order for companies to be competitive in this fast-changing market.
\end{abstract}

Key words: agile project management, customer needs, fast fashion, quick response systems, strategic performance management.

\section{INTRODUCTION}

Looking at the basic structure of the fashion industry until the end of the 1980's, fashion retailers used to rely on their ability to predict fashion trends and the demand of customers well in advance of the moment when these products would actually be available on the market (Guercini, 2001).

Until the mid-1980's, success in the retail industry was achieved through low costs and mass-production of standard designs that did not change often. It is obvious that the demand for basic products then was bigger than that of a variety of designs.

The lifespan of new fashion is quite short. During the 80 's, the fashion calendar was based on exhibitions of materials, fashion shows, and fairs, which consisted of the basic supply for the Spring/Summer and Autumn/Winter seasons, resulting in the need to create the whole season's supply in one batch. At the beginning of the 90 's, fashion retailers began concentrating on expanding the variety of their products by refreshing designs and reacting faster to the newest trends. In order to introduce more variety to the fashion industry, they needed to add three to five additional seasons to the basic fashion calendar. This put a lot of pressure on fashion companies to deliver their clothes in smaller batches and in shorter lead times (Tyler, Heeley, \& Bhamra, 2006). This way, the fashion industry developed an infrastructure with an accent on fast reactions through the shortening of lead times, while maintaining low costs (Hansson, 2011). Fast changes in this industry required fashion retailers to seek suppliers who were able to deliver new products to stores in the shortest possible period of time (Bruce, \& Daly, 2006). This started the trend of outsourcing production to Third World countries with low wages, as this enabled them to cut the costs (Tyler, et al., 2006).

Along with the benefits in terms of lower costs, this outsourcing brings with itself much longer lead times, complicated supply chains because of geographical distances, and complex import and export procedures (Bruce, \& Daly, 2006). Tyler, Heeley, and Bhamra (2006) state that the key players in the supply chain (textile designers, fashion designers, manufacturers, and retail customers) all work consecutively, which results in higher costs, inefficient communication, and other problems. Owing to this lack of speed, fashion companies were unable to sell their products in the right season, which largely affected profits (Fiorito, May, \& 
Straughne, 1995). In addition to this, the lifestyles and demand of customers in fashion began changing in a rapid way.

Information and trends travel around the world at an incredible speed these days, which results in customers having more variety and being able to buy fashion products more often. The changes in lifestyle in the sense of social and cultural factors, as well as the need to be unique, forced companies to constantly place new and refreshed fashion lines, to be able to compete on the growing market.

The following characteristics are common for today's fashion industry (Christopher, Lowson, \& Peck, 2004):

1. Short product lifespan - the period of time in which it is possible to sell a fashion product is very short and seasonal, measured in months or even weeks.

2. Volatility - the demand for products is rarely stable. This is because of the influence of a number of factors, from weather conditions, to costumes in movies, to what celebrities are wearing.

3. Unpredictability - because of frequent changes, it is very hard to accurately predict the demand for a certain product line in a certain period of time.

4. Impulsive buying - a customer's decision to purchase a product is often at the exact point of sale. In other words, the product stimulates the customer in real life, so there is a need for the right products to be available at the right time.

These days, the fashion industry aims to attract customers to stores as often as possible, as to ensure that customers will buy more. The production of modern clothes requires shorter market cycles, highly flexible production and design, and the transformation of raw materials into trendy fashion articles in very short lead times (Hu, Li, Chen, \& Wang, 2014).

This all resulted in the restructuring of the fashion industry in order to improve operational performance (Taplin, 2006). Some of the strategies that fashion companies have adopted during the 90's are Just-in-Time methods and Quick Response Systems with shorter lead times. In order to be profitable in this industry, fashion retailers have to adopt the philosophy of "fast time to market". Agility through the focus on the customers' preferences in the design process and the process of the development of products additionally enhance profitability (Bhardwaj, $\&$ Fairhurst, 2010).

\section{THE PHENOMENON OF FAST FASHION}

Today, fashion companies are focused on getting a competitive advantage but the spotlight is no longer on prices - it is now more important to cater to the customers' needs (Sheridan, Moore, \& Nobbs, 2006). Still, it isn't enough to just cater to their needs, but to place the desired products at the right time in order to make them available at the moment when the customers want them. (Christopher, et al., 2004).

Customers today are willing to spend less money per piece of clothing than before, but they are also ready to buy more products, more often (Nordas, 2004). Because of this, fashion retailers need to provide a large amount of different products in terms of colors, size, design, etc., and offer these products often to be able to meet the customers' needs.

Modern times have created a market where fashion companies have to compete among themselves in providing shorter lead times, placing new trends that are seen on runways in their stores at an extreme speed. These fashion companies are considered the founders of fast fashion, which is the result of the process of shortening lead times (Taplin, 1999). The constant need to refresh the supply of products has made it mandatory for fashion companies to have a higher number of seasons, or more specifically, to accelerate the dynamic by which a whole collection is replaced in a store. By introducing these short-term clothing lines, fashion companies make their consumers visit their stores more often. The consumers' desire to momentarily satisfy their needs, along with lower prices, has motivated them to prefer retailers such as Zara or H\&M (Bhardwaj, Fairhurst, 2010) to other retailers.

The fashion industry today is very competitive and there is a constant need for refreshing the product offer, which results in the need to have a higher number of seasons. In extreme cases, 
there can be as much as 20 seasons per year, which is the case with Zara. Shorter lead times mean that the time frame that needs to be predicted is shorter, so the probability of mistakes in these forecasts is lower.

The fast fashion industry uses many innovative strategies. Fashion companies face a very competitive environment and they need to react to the customers' needs, which are becoming more and more complex. In order to stay competitive, companies rely on sophisticated information systems, logistics, and prediction systems.

Bhardwaj and Fairhurst describe the fast fashion market as a market with a large number of seasons, which puts pressure on suppliers to deliver fashion items in smaller batches and in shorter periods of time. Fashion companies such as Zara have changed their strategies to adapt easily to the latest trends that are seen on runways and they introduce their own interpretations of the newest designs to their stores in three to five weeks in order to attract customers (Hu, et al., 2014).

\section{CHARACTERISTICS OF FAST FASHION SYSTEMS}

Fast fashion is characterized by the shortening of lead times within its supply chains, as well as by offering more variety to its customers by constantly adding new products to its stores (Hansson, 2011). Companies such as Zara, $\mathrm{H} \& \mathrm{M}$, and Benetton were the first to apply the fast fashion system. This system consists of a minimum of two components (Cachon, \& Swinney, 2011):

1. Short production and distribution lead times (later explained as QR method),

2. Design of very trendy products (enhanced design technique).

Short lead times are possible with the combination of localized production, sophisticated information systems, and quick distribution methods. For example, Zara produces most of its products in expensive European and North African factories (instead of outsourcing its production to cheaper Asian factories), but is able to continuously control the stock in its stores and to adequately adapt its supply to the demand (Ghemawat, \& Nueno, 2006).
The second component, the design of trendy products, is enabled through the thorough monitoring of the industry and customers' tastes, as well as through the shortening of lead times, all of which requires enhanced design techniques.

QR systems have shown to be a successful tool with which companies can easily adapt their offer to the market demand, as well as to influence the customers' behaviors by reducing the number of sales periods at the end of seasons. There is a trend among customers, especially in the fashion industry, to delay their purchase in hopes of an upcoming sale, which is a problem for retailers. This type of customer behavior affects profitability. Both QR systems and enhanced design techniques are considered tools with which this kind of strategic customer behavior can be prevented.

Enhanced design techniques give customers modern clothes, which they value more, so the probability of customers risking their desired product to be unavailable in the periods of sales is lower. QR reduces the probability of clothing being available in stock until the sales periods, because this strategy adapts the supply to demand. These two techniques therefore enable fashion companies to set higher prices, while still motivating customers to buy their products despite these high prices.

Both QR systems and enhanced design techniques are tools that are used when applying agile project management in a company's core. Because of the fast pace with which the fashion industry changes and the high level of different risks, mainly because of the certainty of a certain product's success, agility is crucial for a fashion company's success.

\section{SUPPLY CHAINS OF FAST FASHION}

The modern fashion market is a highly competitive market characterized by customers' constant need for new products and new trends (Christopher, et al, 2004). Prices aren't enough for companies to be able to compete on the market, and the speed with which they make decisions on products is of key importance for catering to the expectations and desires of customers. 
During the 1980's, the usual lead time in the fashion industry was around 66 weeks, meaning that this was the time necessary for transforming raw materials to products available to customers. Only 11 out of these 66 weeks were tied to production, while the rest of the time was used for planning, transportation, documentation, etc. Today, such a lead time would be completely unprofitable for fashion companies.

There are four potential operative systems in today's fashion industry (Cachon, \& Swinney, 2011):

- Traditional systems, which are characteristic for typical companies that have long production and realization periods, and have standard design capabilities,

- Quick response systems (QR), which do not implement enhanced design techniques, but have considerably shorter lead times for production and realization,

- Enhanced design systems, which have innovative design, and thus stimulate customers to be ready to pay a higher price, but still have long lead times, and

- Fast fashion systems, which implement both QR and enhanced design. These are the systems that popular fashion companies such as Zara, H\&M, and Benetton use.

New operative systems that fast fashion companies use were developed in the fashion industry because of the need to react quickly to changes on the fashion market. An efficient supply chain can lead to shorter lead times, and reduce the amount of errors in forecasting trends (Jacobs, 2006).

A traditional system is usually described as part of the supply chain that is supply-oriented, while new operative systems are described as parts of the supply chain that are demandoriented. Fast fashion companies are also demand-oriented (Jacobs, 2006).

The traditional supply chain uses a "push strategy", in which production starts without taking into account what customers want. In other words, products are offered to customers regardless of whether they actually want them or not. Companies that use this strategy usually get into mass production which leads to large amounts of stock. On one hand, this stock can be a type of insurance in case demand for a certain product is high. On the other, stock can have a negative financial impact because these products will later be sold at sales prices (Christopher, Harrison, \& Van Hoek, 1999).

Fast fashion has swapped push strategies with "pull strategies" (Barnes, \& Lea-Greenwood, 2010). Fashion companies notice and document trends and customer needs and according to them place products on the market in the shortest possible time.

There are many factors that have created the need for fashion companies to implement new strategies and to change their supply chains. Some of these factors are shorter product life spans, high levels of impulsive purchases, and the ever-changing opinions and tastes of customers.

Strategies such as QR and Agile Supply Chains have enabled fashion companies to satisfy the needs of customers. Time, agility, and making decisions based on the market are the key dimensions of these two strategic concepts of the contemporary fashion industry.

\section{LEAD TIMES}

In order to better understand the strategies used in fast fashion, it is important to understand the term "lead time". This term is of key importance for fast fashion, since it is in the focus of fast fashion to reduce this time.

Generally, the term lead time means the time it takes for the realization of a product, or more specifically, the time that it takes to transform the idea of a product to its physical placement on retail shelves, where it is available to customers.

There are three critical lead times which companies have to manage if they want to be able to compete in the fashion industry (Čiarniene, \& Vienažindiene, 2014):

1. Time to market - the time necessary for a company to notice a possibility on the market 
and to translate it to a product and offer it on the market,

2. Time to service - the time it takes to document a customer's order and for the product to be delivered to retail, and

3. Time to reaction - the time necessary for a company's outputs to be adapted as a reaction to changes in demand.

\subsection{Time to Market}

In markets with short product life span, the ability to notice trends quickly and to translate them to products in retail in the shortest possible time has become a precondition for success. Companies whose time to market is too long miss out on two fields. First, they miss important opportunities for sales, which are probably not going to occur a second time. Second, these companies will probably face situations in which by the time a product finally arrives to retail points, the demand has already begun declining.

New ways of formulating production strategies, which focus on flexibility and reducing the number of identical products, have obviously helped companies shorten their time to market. New technologies such as CAM (Computer Aided Manufacturing) and CAD (Computer Aided Design) have additionally helped in modifying products as seasons and product life cycles have already unfolded.

\subsection{Time to Service}

Earlier, retail stores in the fashion industry used to place orders to their suppliers many months, up to nine, before the beginning of the season. This often led to delivering irrelevant products and the accumulation of stock.

The reason for placing orders so much in advance was not the time necessary for production or transport, but the number of steps from the moment the decision about ordering a product was made, and collecting the necessary documentation, etc. When a manufacturer is located in a different geographical area, collecting the right documents, integrating full trucks of products, going through customs checks, and the actual transportation of products consumes a lot of time.
Production was moved to Third World countries to minimize costs. On the other hand, the real problem lies in the costs of the entire supply chain, costs of stock and of scarce products.

\subsection{Time to Reaction}

Ideally, every organization would be able to adapt their offer based on people's needs, and at the time and place when customers need a product. Next to the two critical times that we have already explained, there is another issue which companies face in their desire to react to demand, and this is the fact that they often notice changes in real demand too late. Real demand is what customers buy and seek every hour, every day. Most supply chains are based on orders, which are based on predictions and forecasts, and some supply chains don't even have the ability to monitor the final market place, the points of sale.

A key problem that many companies face, not only in the fashion industry, is the time it takes to obtain materials, transform them to products, and transport them to the points of sale, which is much longer than the time that a customer is willing to wait for that product.

\section{AGILE SUPPLY CHAINS}

The fashion industry is unpredictable and goes through frequent changes, so it is appropriate for this industry to use agile supply chains.

The term of agility in the context of supply chains is important in the sense of quick responses. Conventional supply chains in the fashion industry were long with long lead times, and this is the reason why they were based on forecasting. Agile supply chains are shorter and try to be based on demand. Conventional supply chains are based on stock, while agile supply chains are based on information.

Christopher, Harrison, and Van Hoek (1999) point to a couple of key characteristics of the agile supply chain. They include:

1. Market sensitivity - it is closely connected to the tastes and needs of customers, 
2. Virtual integration - it relies on collecting information from all of the entities in the chain,

3. Network-based - it is flexible thanks to the efforts of individuals and specialists in the chain, and

4. Process alignment - there is a high level of inter-connectivity between the processes of all of the members in the network.

\subsection{Market Sensitivity}

The goal of every market-oriented company has always been to be close to the customer, but for fashion companies this is of key importance. Successful fashion companies notice trends while they are developing. Data from points of sale are analyzed daily and used to figure out which products should be kept, in order for their production to be repeated, so to ensure that the product continues to be available. Still, sometimes the selling season of a product is meant to be short, so noticing the customers' preferences and needs should always be a priority. The fashion company Zara engages its sales people to keep track of which products customers like and don't like, and this information is sent to design teams. Using CAD and CAM, these ideas can quickly be transformed into physical products and be placed on the market in just a few weeks.

\subsection{Virtual Integration}

The agile supply chain is virtual in the sense that it is connected and integrated through sharing information about the actual demand, so all of the participants in the chain work together. Retailers and their suppliers have to be much more closely connected than it was necessary before. Until recently, just a small number of retailers in any industry would share information from their points of sale with their suppliers. Now, there is an awareness about the importance of sharing this type of information and about the fact that doing this can lead toward large availability of products on shelves with little stock.

\subsection{Network-Based Nature}

It is characteristic for agile companies to use flexibility in their relationships with their large base of suppliers. For example, Zara has achieved a high level of responsiveness to customer needs by cooperating closely with specialized, smaller manufacturers. Zara's strategy is to work on processes that lead to lowering costs through economies of scale in its own premises (processes such as coloring, cutting, packaging). All other manufacturing activities are done by a network of 300 smaller manufacturers, of which each is specialized for a specific part of the production process or a certain type of clothing. These manufacturers work exclusively for Zara's mother company, Inditex. In return, they get all of the financial, logistical, and technical support they need in order to achieve their goals in terms of time and quality. The system is flexible enough to react on time to fast changes in demand.

\subsection{Process Alignment}

Responsive supply chains need a high level of process alignment both internally in the company, as well as with all of the companies that they cooperate with. The term aligned processes refers to the ability to create relationships without borders, so as to not delay processes due to buffers between different phases in the supply chain. In the agile network, process alignment is critical and is made possible owing to various software that are internet-based, which allow various participants in the chain to be connected. Now it is possible for organizations, which are in different geographical locations and which are independent in terms of ownership, to act as if they were one company.

In the fashion industry, there is a large number of participants in the process that begins with product design and ends with the physical transport of a product to retail shelves. Coordinating and integrating the information flow and material is critical if there is a goal to achieve quick reactions to the ever-changing fashion industry.

\section{QUICK RESPONSE METHOD}

Quick Response (QR), is a method that has been accepted in the fashion industry as one with which it is easier to reach agility and quicker reactions. Today, QR is defined as an operational strategy (Lowson, 2002). QR is important as a strategy in the fashion industry because it can handle the complex logistics of 
fashion, as well as put a stop to outsourcing production to countries with lower wages in other parts of the world.

Sheridan (Sheridan, et al., 2006) defines the QR strategy as a customer oriented strategy which requires detailed planning by all of the partners in the supply chain, which enables products to be produced at the right time in the right place, using information technologies and flexible production in order to eliminate errors in the entire supply chain.

For many industries, demand is becoming chaotic due to consumers' large appetites for differentiated products. One of the biggest benefits of $\mathrm{QR}$ is the ability to reduce the time necessary for procurement.

QR can be defined as: A state of responsiveness and flexibility in which companies want to produce a highly diverse product portfolio for customers in the exact amount, quality, and variety, as well as at the right time, place, and at the right price which is dictated by the demand of real customers. QR enables the ability to make the right decisions based on demand in final moments, leading to maximizing the diversity of supply, while minimizing lead times, cost, and stock (Lowson, King, \& Hunter, 1999).

QR requires a few strategic preconditions (Christopher, Lowson, \& Peck, 2004):

The alignment of organizational activity to demand. This is a key principle of QR. All activities have to be in line with the demand and behavior of customers. Products are produced and delivered in the amounts that are in line with demand.

Links between supply and demand. For $\mathrm{QR}$ it is very important to strategically understand the driving forces of demand and their links with supply are of key importance.

Demand relationships. QR understands that both customers and products are dynamic and make unique demands for the organization.

Resource configuration. In $\mathrm{QR}$, this strategic architecture is inter-organizational. Strategy and strategic thinking are at a level of the whole network. In this configuration it is necessary to add mapping customer values and their view of the organization into operational activities.
Time. Fast and precise adapting to changes in the fashion market is probably the most important element of the QR strategy.

Primacy of information. Data and information are at the base of QR. Precise and timely information flows will lead to quick and accurate results without waste and unnecessary costs.

Partnerships and alliances. Performance is more and more dependent on alliances and relationships with other organizations as a way to handle volatile markets.

\section{CONCLUSION}

Taking into account the "Six Principles of Agile Project Management" (White, 2008) and the strategies and techniques that fast fashion companies use that have been discussed in this article, we can see in which way the modern fashion industry requires and uses agile project management practices.

The six principles of agile project management are (White, 2008):

1. Close interaction between the customer/user and the developers. According to White, the customer is the final decision maker in agile projects. We can see how this is applied in fast fashion projects, where the season's product portfolio is constantly adjusted and improved to fit the customers' wants and needs. QR systems allow for this to happen, ensuring that production is flexible and that fashion companies can produce a highly differentiated product portfolio in the exact amount, quality, and variety that meets demand.

2. Less time dedicated to planning at the beginning of the project.The agile supply chains used in fast fashion are shorter with shorter lead times than traditional ones. At the beginning of a fashion project, less time is spent on planning, because product success is uncertain. This allows for flexibility and constant adjustment of the fashion season's offer, all taking into account the demand for certain designs, sizes, and variety. As is the case with agile 
projects, "each iteration adds a set of features to the final product" (White, 2008).

3. Smaller teams, more highly skilled team members. During their project cycle, fast fashion companies rely on network-based and virtually integrated supply chains. As mentioned before, companies such as Zara have large networks of smaller manufacturers who are specialized for a specific part of the production process or a certain type of clothing. These manufacturers' dedication to a smaller, but integral part of the production process allows them to focus on specific goals and lower the risk of error, and the support they get from the companies' headquarters allows them to not waste time on financial or logistical problems (Jovanović, Mihić, Damnjanović, 2013).

4. Delayed decision making. Delayed decision making is applicable to fast fashion projects in the sense that only a small part of the upcoming season's product portfolio is planned ahead. The products are then tested to see how customers react to them, and the feedback fashion headquarters get from their points of sale is used to tweak and adjust the following batch of products that will be launched. In Zara, for example, this process is repeated in several iterations throughout the season.

5. Adaptive leadership. White explains how agile project management "supports continuous learning about what the next project activities should be, while adapting to changing environments" (White, 2008). Based on the research presented in this paper, it can be concluded that this is exactly what successful fast fashion companies do - they continuously collect information from their customers and other entities in the whole production process and adapt the outcomes of their project activities to fit what the customers want.
6. Elimination of activities that don't contribute value. Fast fashion companies eliminate their waste and build quality into their products as they are produced, instead of testing them after the fact. As explained, they do this by producing smaller batches of the same product and limiting their initial time on the market to a shorter period, after which it will be decided whether the product will be renewed and under what circumstances.

It can be concluded that agile project management is very applicable, even necessary, in the fast fashion industry. Following agile project management principles and using strategies such as QR systems and agile supply chains, modern fashion companies are able to provide value to their customers and stay competitive in this fast-changing market.

\section{REFERENCES}

Barnes, L., \& Lea-Greenwood, G. (2010). Fast fashion in the retail store environment. International Journal of Retail \& Distribution Management, 38(10), 760772.

Bhamra, T., Heeley, J., \& Tyler, D. (2006). "Supply chain influences on new product development in fashion clothing". Journal of Fashion Marketing and Management: An International Journal, 10(3), 316-328.

Bhardwaj, V., \& Fairhurst, A. (2010). Fast fashion: response to changes in the fashion industry. The International Review of Retail, Distribution and Consumer Research, 20(1), 165-173.

Birtwistle, G., \& Fiorito, S. S., \& Siddiqui, N. (2003). Quick response: perceptions of UK fashion retailers. International Journal of Retail \& Distribution Management, 31(2), 118-128.

Bruce, M., \& Daly, L. (2006). Buyer behaviour for fast fashion. Journal of Fashion Marketing and Management: An International Journal, 10(3), 329-344.

Cachon, G. P., \& Swinney, R. (2011). The Value of Fast Fashion: Quick Response, Enhanced Design, and Strategic Consumer Behaviour. Management Science, 57(4), 778-795. 
Chen, X. J., Hu, Z. H., Li, Q., \& Wang, Y. F. (2014). "Sustainable Rent-Based ClosedLoop Supply Chain for Fashion Products". Sustainability, 6, 7063-7088.

Christopher, M., Harrison, A., \& Van Hoek, R. (1999). Creating the Agile Supply Chain. Institute of Logistics \& Transport, UK

Christopher, M., Lowson, R., \& Peck, H. (2004). Creating Agile Supply Chains in the Fashion Industry. International Journal of Retail and Distribution Management, 32(8), 367-376.

Čiarniene, R., \& Vienažindiene, M. (2014). Management of contemporary fashion industry: characteristics and challenges. Procedia - Social and Behavioural Sciences, 156, 63-68.

Fiorito, S., May, E., \& Straughne, K. (1995). Quick response in retailing: components and implementation. International Journal of Retail Distribution, 23(5), 1221.

Ghemawat, P., Nueno, J. L. (2006). "Zara: Fast Fashion", Harvard Business School

Guercini, S. (2001). Relation between branding and growth of the firm in new quick fashion formulas: analysis of an Italian case. Journal of Fashion Marketing and Management: An International Journal, 5(1).

Hansson, M. (2011). What impact has a fast fashion strategy on fashion companies' supply chain management?. Master Thesis, Halmstad University

Jacobs, D. (2006). The promise of demand chain management in fashion. Journal of Fashion Marketing and Management: An International Journal, 10(1), 84-96.

Jovanović, A, Mihić, M, \& Damnjanović, V. (2013). Adaptacija ponude na lokalnom tržištu - Studija slučaja Terranova Srbija. Marketing, 44(2), Srpsko udruženje za marketing, Beograd, ISSN 0354-3471, 173-183.

Lowson, R. H., King, R., Hunter, N. A. (1999). "Quick response: managing the supply chain to meet consumer demand". John Wiley \& Sons: Chichester.

Lowson, R. H. (2002). "Strategic Operations Management: the new competitive advantage”. Routledge: London.
Moore, C., Nobbs, K., \& Sheridan, M. (2006). "Fast Fashion requires fast marketing". Journal of Fashion Marketing and Management, 10(3), 301-315.

Nordås, H. K. (2004). "The Global Textile and Clothing Industry post the Agreement on Textiles and Clothing", World Trade Organization

Tyler, D., Heeley, J., \& Bhamra, T. (2006). Supply chain influences on new product development in fashion clothing. Journal of Fashion Marketing and Management: An International Journal, 10(3), 316-328.

Taplin, I. M. (1999). "Continuity and change in the US apparel industry: A statistical profile", Journal of Fashion Marketing and Management, 3(4), 360-368.

Taplin, I. M. (2006). "Restructuring and reconfiguration: The EU textile and clothing industry adapts to change". European Business Review, 18(3), 172186.

White, K. R. J. (2008). Agile project management: A mandate for the changing business environment. Paper presented at PMI Global Congress 2008-North America, Denver, CO. Newtown Square, PA: Project Management Institute.

https://www.apparelbusiness.com/the-life-ofa-garment-from-seed-to-sale-6-steps-inthe-fashion-supply-chain/ - visited 31.08.2018.

https://www.bernardmarr.com/ - visited 03.08.2018.

https://www.clearreview.com/what-iseffective-performance-management/ visited 16.07.2018.

https://www.ecommerceplatforms.com/articles/ecommercestatistics - visited 10.09.2018.

https://www.forbes.com/sites/stevedenning/20 15/03/13/how-agile-and-zara-aretransforming-the-us-fashion-industry/ visited 17.04.2018.

https://www.home.howstuffworks.com/homedecor/decorating-styles-techniques/howis-fabric-created2.htm - $\quad$ visited 30.08.2018.

http://www.nytimes.com/2004/12/04/business /04markdown.html - visited 11.09.2018.

https://www.rankia.com/blog/mundodelaempr esa/1110169-empresas-inditex-the- 
fashionable-company-in-english - visited http://www.trendwatching.com/about/inmedia 12.04.2018.

/articles/2009_fast_fashion.html

https://www.sbmldanielle.wordpress.com/201 7/06/02/blog-post-title-2/ - visited https://www.wsj.com/articles/inditex-profit12.07.2018. boosted-by-zara-stores-1457512394 visited 14.04.2018.

https://www.textileschool.com/289/apparel-

manufacturing-processes/ - visited 22.08.2018. 